\title{
RELIABILITY OF THE GERMAN LANGUAGE VERSION OF THE PRESCHOOL AND KINDERGARTEN BEHAVIOR SCALES SECOND EDITION
}

\author{
${ }^{1}$ Aida Al Awmleh and ${ }^{2}$ Alexander Woll \\ ${ }^{1}$ Department of Instruction and Supervision, Faculty of Physical Education, The University of Jordan, Jordan \\ ${ }^{2}$ Department of Sport Sciences Germany, University of Konstanz, Germany
}

Received 2012-09-06, Revised 2013-07-01; Accepted 2013-07-01

\begin{abstract}
The purpose of this study was to examine the reliability and validity of the English and German language versions of the behavior rating scale, Preschool and Kindergarten Behavior Scales, Second Edition (PKBS2) and make a comparison between them. Data were collected from (37) preschool-age children using both the English and German versions. Internal consistency, testing and retesting, alternate [language] versions and standard error of measurement were used to evaluate the reliability of the German-English (PKBS-2) versions. The alpha and split-half coefficients for the German (PKBS-2) total scores range from 0.94 to 0.96. After three weeks, bivariate Pearson correlations indicate that the resulting coefficients of stability are significant at the (0.001) level and the test-retest reliabilities for problem behavior scores are higher than social skills scores in both the German and English versions. The reliability coefficients for social skills were 0.63 for the 3-week retest in the English version and 0.61 for the retest in German; the coefficients for problem behavior were 0.83 using the English version and 0.81 in German.
\end{abstract}

Keywords: Reliability, PKBS-2, German Language Version, Preschool and Kindergarten Behavior

\section{INTRODUCTION}

Social and emotional functions play an important role in child development. The Preschool and Kindergarten Behavior Scales Second Edition (PKBS-2) is commonly used to gather information about social and emotional functioning. Brassard and Boehm (2011) indicated that PKBS-2 has excellent psychometric characteristics as a brief screening measure. If routine screening is the purpose of the assessment, or an examiner is interested in ruling out other potential problems, the nonpathologizing PKBS-2 is a good choice. Furthermore, Bracken et al. (1998) investigated the psychometric qualities of 13 preschool third-party measurement tools of social-emotional functioning and found that third-party measurement tools are psychometrically strong and the BASC, PKBS, SSRS,
Vineland have the best technical characteristics. A few assessment instruments available in the German language assess the typical, general and routine social competencies and problem behavior of young children. Thus it is important to recognize that the translation of test items is comparable in manner with the original items and that tests are suitably specific to culture. The reliability of the original behavior scale (PKBS-2) was determined by Merrell (2002), who stated that the alpha and split-half coefficients for total scores ranged from 0.90 to 0.97 . Salvia et al. (2010) recommend that in order to achieve a sufficiently reliable level of reliability, the minimum standard should be 0.90 for tests used to make important educational decisions for students. Merrell (2002) examined the validity of the PKBS and the results indicated strong evidence of content validity and construct validity, relations to other variables and

Corresponding Author: Aida Al Awmleh, Department of Instruction and Supervision, Faculty of Physical Education, The University of Jordan, Jordan 
consequences of assessment. Furthermore, studies carried out by Holland and Merrell (1998) have provided additional support for the validity of the PKBS. Carney and Merrell (2002) found that English and Spanish versions of PKBS were reliable for rating both social skills and problem behavior: internal consistency scores were (0.93) for social skills and (0.96) for problem behavior; correlations between [language] versions for social skills scores were (0.93), while problem behavior scored at (0.94). In addition, Allin (2004) recommended PSKBS for research purposes and for screening children thought to be at risk for developing social or behavioral problems. Pierangelo and Giuliani (2006) indicated that the strength of PKBS-2 is that it is standardized thanks to its nationwide sample of ratings of 3313 children. Further strengths are found in its wide variety of reliability and validity evidence in support of the testing of social and emotional characteristics (Maddox, 2008). The purpose of the current study is to examine the relationship between the German and English language versions in order to satisfy reliability and validity requirements.

\section{MATERIALS AND METHODS}

\subsection{Participants and Procedure}

Participants were parents and teachers of (37) preschool children (males (21), females (16), mean 4.5 (SD $=0.7$ ) enrolled in South German preschools, in the towns of Konstanz and Radolfzell. Fluency in both the English and German languages was required. Participants were asked to rate their children using separate language English and German versions after three weeks retest. The research packets were randomly distributed during the period from July 7-9 and 12 July to 28-August 2007. Four methods were used to determine the reliability of the German and English versions of the scale (PKBS-2) and consisted of testretesting, alternate [language] versions, internal consistency And Standard Error of Measurement (SEM).

\subsection{Development of German Language (PKBS- 2) Version}

Permission for translation into the German language was provided by Pro.ed, an international publisher. The German language version of PKBS-2 was translated independently by two bilingual students from the Department of Linguistics at the University of Konstanz. A professor and four doctoral students, who are fluent in English, independently compared the translation results. The German PKBS-2 was also compared by a teacher of German at the Department of Linguistics, who is bilingual (English and German).
Table 1. English and German PKBS-2 form section

\begin{tabular}{lcl}
\hline $\begin{array}{l}\text { Wird von anderen Kindem } \\
\text { zum Mitspielen aufgefordert }\end{array}$ & 11 & $\begin{array}{l}\text { Is invited by other } \\
\text { children to play } \\
\text { Weiß seine freizeit } \\
\text { sinnvoll zu gestalten }\end{array}$ \\
$\begin{array}{l}\text { Kann sich relativ gut von } \\
\text { einem Elternteil trennen }\end{array}$ & 12 & $\begin{array}{l}\text { Uses free time in an } \\
\text { acceptable way } \\
\text { Is able to separate from } \\
\text { parent without } \\
\text { extreme distress }\end{array}$ \\
$\begin{array}{l}\text { Beteiligt sich an Gesprachen } \\
\text { in der Familie oder in } \\
\text { der Gruppe }\end{array}$ & 14 & $\begin{array}{l}\text { Participates in family or } \\
\text { classroom discussions }\end{array}$ \\
$\begin{array}{l}\text { Bittet bei Bedarf } \\
\text { Erwachsene um Hilfe }\end{array}$ & 15 & $\begin{array}{l}\text { Asks for help from adults } \\
\text { when needed }\end{array}$ \\
\hline
\end{tabular}

The finally-obtained results were compared and corrected independently by two professors from the Department of Social Science and the Department of Social Psychology and Motivation, who are bilingual. They compared the final translations and dimensions to assure acceptable social validity and comparability of intent with the English language. Table 1 shows the similarity between languages.

\subsection{Instrument}

The Preschool and Kindergarten Behavior Scales Second Edition (PKBS-2) is a norm-referenced, standardized rating scale that can be completed by parents or teachers. It was developed between 1992 and 2000 (Merrell, 1994).

PKBS-2 is a 76-item behavior rating scale designed to measure both social and emotional problems and is useful for assessing children with significant behavioural, social, emotional and development problems, (Fig. 1). Score conversion tables are provided for home raters and school raters to measure a separate domain:

- 34-item social skills scale that describes positive behaviours. Higher social skills scores indicate greater levels of social adjustment

- 42-item problem behaviour scale that is designed to reflect the internalizing and externalizing of problems. Higher problem behaviour scores indicate greater levels of problem behaviour

The social skills scales are divided into the following subscales: Social cooperation items (12): describe cooperative and self-restraint behaviours, pertaining to those behaviour characteristics that are important when having to follow instructions from adults.

Social interaction items (11): reflect social initiation behaviours, which are important in gaining and maintaining acceptance and friendship from others. 


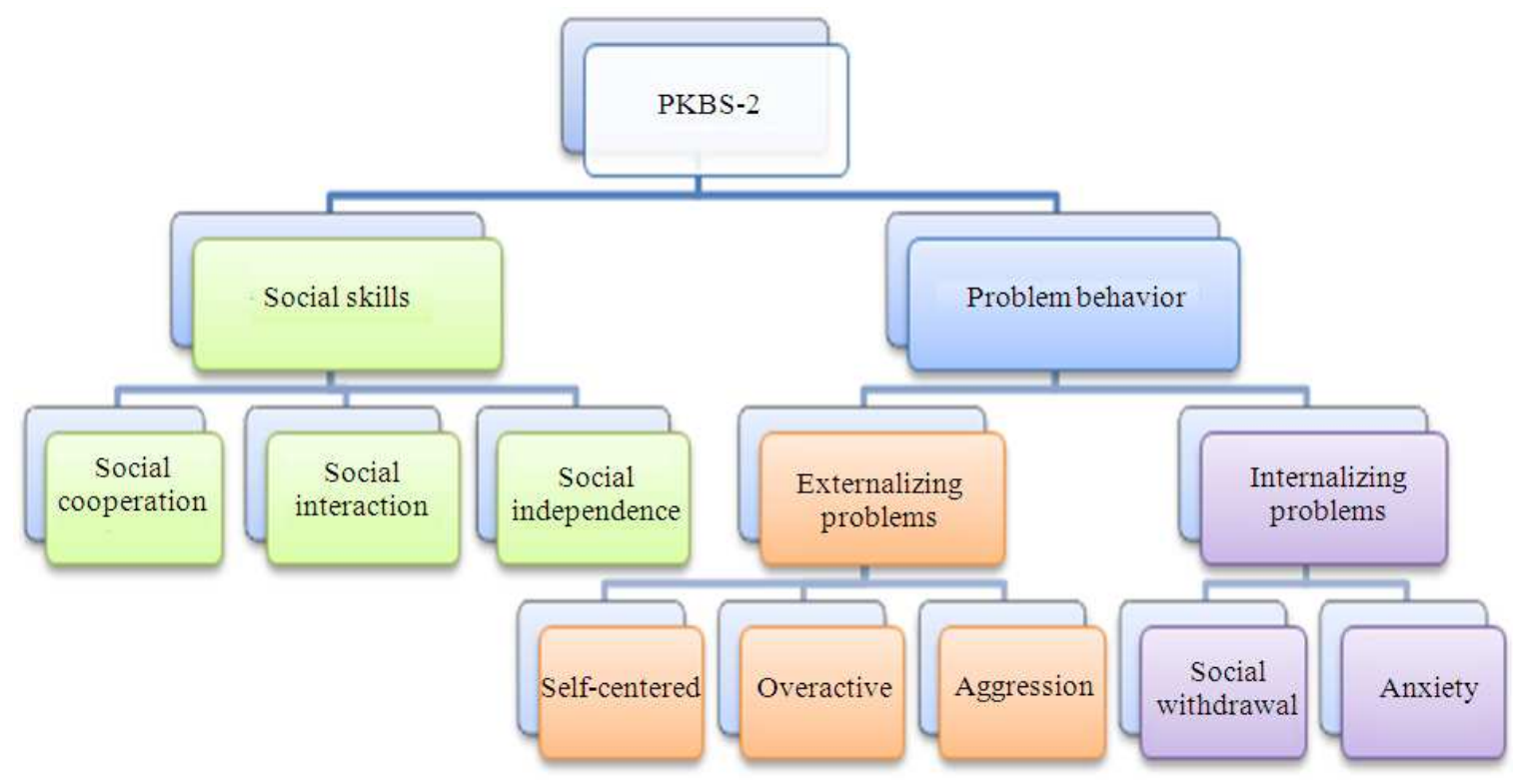

Fig. 1. Dimensions of the PKBS-2

Table 2. Internal consistency (alpha and split-half) reliability raw score Standard Error of Measurement (SEM) estimates for the total German (PKBS-2) sample (37) pre test

\begin{tabular}{llllr}
\hline PKBS-2 scores & Coefficient alpha & Split-half & SEM & Std \\
\hline Social skills scale & 0.92 & 0.91 & 1.70 & 6.2 \\
Social cooperation & 0.95 & 0.92 & 1.80 & 8.3 \\
Social interaction & 0.91 & 0.88 & 1.70 & 5.8 \\
Social independences & 0.96 & 0.94 & 0.36 & 1.8 \\
Social skills total & & & & \\
Problem behavior scale & & & 5.70 & \\
Externalizing problems & 0.86 & 0.95 & 2.90 & 8.6 \\
Internalizing problems & 0.88 & 0.86 & 4.90 & \\
Problem behavior total & 0.94 & 0.94 & & \\
Supplemental problem behavior subscale & & & 1.80 & 7.1 \\
Self-centered/Explosive & 0.93 & 0.90 & 1.70 & 5.4 \\
Attention problems/Overactive & 0.89 & 0.89 & 1.30 & 4.3 \\
Antisocial/Aggressive & 0.90 & 0.85 & 0.88 & 4.5 \\
Social withdrawal & 0.84 & 0.77 & & 4.6 \\
Anxiety/Somatic problems & 0.83 & & & \\
\hline
\end{tabular}

Social independence items (11): reflect behaviours that are important in gaining independence within the peer group. The problems behaviour scale is divided into two subscales for the internalizing of problems and externalizing of problems. The externalizing subscale includes items (27) that describe acting-out and disruptive under-controlled behaviour problems, such as aggression, over-activity and antisocial behaviours.

The internalizing problems subscale includes items (15) describing over-controlled emotional/behavioural problems, such as social withdrawal, somatic problems, anxiety and behaviours consistent with depressive symptomatology (Merrell, 2002).

\section{RESULTS}

The results indicated strong $(\alpha>0.83)$ internal consistencies in the German version of PKBS-2.Total social skills scores were (0.96) and total problem behavior scores were (0.94). The data in Table 2 shows the internal consistency for both alpha and split-half reliability [coefficients]. Furthermore the Standard Errors 
of Measurement (SEM) scores were (0.36) for social skills and (4.9) for problem behavior. The alternate [language] versions and test and retest results are presented in Table 2. Pearson correlation coefficients indicated that the English and German versions were significantly correlated. The range of the correlation coefficients for total scores is (0.98) for social skills scale and (0.97) for the problem behavior scale. These results indicate a strong evidence of the comparability of parallel of PKBS-2. Bivariate Pearson correlations were also calculated to examine the 3 -week test-retest reliability of the PKBS-2. The results indicated that reliability coefficients for social skills were $(0.63)$ for the English version and (0.61) for German. With regard to problem behavior coefficients for the English version were $(0.83)$ and $(0.81)$ for the German version. These coefficients were significant at the 0.001 level (two- tailed).

\section{DISCUSSION}

The internal consistency scores indicated strong reliability with regard to total social skills (0.96) and total problem behavior (0.94). These results are similar to the internal consistency of social skills (0.93) and problem behavior (0.96) of the English and Spanish versions (Carney and Merrell, 2002). Internal consistency scores for the PKBS-2 supported these results with respect to social skills at (0.96) and problem behavior at (0.97) (Merrell, 2002). A strong relationship between the German and English versions is seen by the fact that the scores for total social skills (0.98) and (0.97) for total problem behavior are correlated. On the other hand Carney and Merrell (2002) determined there to be a strong relationship between the Spanish and English language versions, where scores in both versions were (0.93) for social skills and (0.96) for problem behavior. Allin (2004) indicated that the test-retest data on PKBS-2 were not strong, as results for internal consistency showed moderate top high stability, with coefficients from total scale scores ranging from 0.58 to 0.86 at 3 week intervals and 0.69 and 0.86 for social skills and problem behavior respectively. On the other hand, testretest results of the German and English PKBS-2 versions were retested after three weeks with regard to total social skills and problem behavior: (0.61) and $(0.81)$ respectively for the German version and $(0.63)$ on social skills and $(0.83)$ on problem behavior for the English version. These scores are higher than the original PKBS-2 retest reliability results. However lower reliability scores were recorded with regard to internalizing problems dimensions, anxiety, social cooperation and social independence. The social- emotional assessment instruments are generally not expected to evidence extremely strong test-retest reliability as there is more variability across time in the construct of interest (Merrell, 1996; 1999; 2002).

The current study found that test-retest reliabilities for problem behavior scores are higher than social skills scores in both the German and English versions. Merrell (2002) indicated that in early childhood/preschool populations, behaviors relating to social competence may be less stable over time in comparison to problem behavior. Changes in temperament over time may be influenced by both biological and environmental factors (Oberklaid et al., 1991; Hughes et al., 2002) or because prosocial behavior is not observed as often as problem behavior, parents or teachers remember and observe annoying behavior more than good behavior and may subsequently try to find a solution for it. This process is undertaken more often in comparison to children indicating good behavior and therefore may seem to be a normal process. Finally the Standard Errors of Measurement (SEM) scores were small: (0.36) for social skills and (4.9) for problem behavior and indicate the minimum difference between PKBS-2 scores.

\section{CONCLUSION}

To conclude, evidence of acceptable reliability and validity determined the internal consistency coefficient, test-retest stability coefficient and split-half test reliability. In addition, standard error of measurement findings suggests that the validity and reliability of PKBS-2 is adequate and can be used to assess the social and emotional behavior of young children in German preschools and kindergarten.

\section{REFERENCES}

Allin, J.D., 2004. Preschool and kindergarten behavior scales. J. Psychoeducational Assess., 22: 81-86.

Bracken, B.A., L.K. Keith and K.C. Walker, 1998. Assessment of preschool behavior and socialemotional functioning: A review of thirteen thirdparty instruments. J. Psychoeducational Assess., 16: 153-169. DOI: 10.1177/073428299801600204

Brassard, M.R. and A.E. Boehm, 2011. Preschool Assessment: Principles and Practices. 1st Edn., Guilford Press, New York, ISBN-10: 1593857381, pp: 658 .

Carney, A.G. and K.W. Merrell, 2002. Reliability and comparability of a Spanish-language form of the preschool and kindergarten behavior scales. Psychol. Schools, 39: 367-373. DOI: 10.1002/pits.10033 
Holland, M.L. and K.W. Merrell, 1998. Social-emotional characteristics of preschool-aged children referred for Child Find screening and assessment: A comparative study. Res. Dev. Disabilities, 19: 167179. PMID: 9547527

Hughes, M.B., J. Shults, J. McGrath and B. MedoffCooper, 2002. Temperament characteristics of premature infants in the first year of life. J. Dev. Behav. Pediatr., 23: 430-435. PMID: 12476073

Maddox, T., 2008. Tests: A Comprehensive Reference for Assessments in Psychology, Education and Business. 6th Edn., Pro-Ed, Austin, TX., ISBN-10: 1416403418, pp: 555.

Merrell, K.W., 1994. Preschool and Kindergarten Behavior Scales: Test Manual. Clinical Psychology Pub., Brandon, ISBN-10: 0884221520, pp: 61.

Merrell, K.W., 1996. Social-emotional assessment in early childhood: The preschool and kindergarten behavior scales. J. Early Intervent., 20: 132-145. DOI: $10.1177 / 105381519602000205$
Merrell, K.W., 1999. Behavioral, Social and emotional assessment of children and adolescents. 3rd End., L. Erlbaum Associates, Mahwah, ISBN-10: 0805828869, pp: 438.

Merrell, K.W., 2002. Preschool and Kindergarten Behavior Scales: PKBS-2. 2nd Edn., PRO-ED, Austin.

Oberklaid, F., J. Sewell, A. Sanson and M. Prior, 1991. Temperament and behavior of preterm infants: A six-year follow-up. Pediatrics, 87: 854-861. PMID: 2034490

Pierangelo, R. and G.A. Giuliani, 2006. The Special Educator's Comprehensive guide to 301 Diagnostic Tests. 1st Edn., Jossey-Bass, San Francisco, CA., ISBN-10: 0787978132, pp: 484.

Salvia, J., J.E. Ysseldyke and S.E. Bolt, 2010. Assessment: In Special and Inclusive Education: In Special and Inclusive Education. 11th Edn., Cengage Learning, Belmont, CA., ISBN-10: 0547134371, pp: 480. 